\title{
Estudo de caracterização geoquímica e das associações de foraminíferos parálicos do sistema estuarino do rio Jequitinhonha, litoral sul da Bahia
}

Isabel Honorata de Souza Azevedo* Simone Souza de Moraes Antônio Fernando de Souza Queiroz Ana Carina Matos Silva Narayana Flora Costa Escobar Fabiany Cruz Gonzaga

Universidade Federal da Bahia (UFBA) Instituto de Geociências (IGEO)

Campus de Ondina,

Salvador - BA - Brasil. 40170-290

${ }^{*}$ Autora correspondente ih.azevedo@uol.com.br

\section{RESUMO}

As associações de foraminíferos, além de serem abundantes e apresentarem ampla distribuição geográfica, aproveitam as peculiaridades intrínsecas desses organismos de armazenarem em suas testas características dos locais onde viveram. Nesse contexto, as testas desses organismos foram relacionadas aos teores de metais-traço do sedimento do sistema estuarino do rio Jequitinhonha, litoral sul da Bahia, com o objetivo de avaliar se os níveis desses elementos estão afetando a microfauna. Foram obtidas, para a região do canal, 281 testas de foraminíferos na primeira campanha $(4,98 \%$ dos espécimes foram coletados vivos; e nenhuma das testas estavam malformadas) pertencentes a 10 espécies, das quais destacam-se Trochammina inflata; Haplophragmoides wilberti e Ammonia beccarii como espécies principais. Na segunda amostragem, não houve registro de foraminíferos, devido às baixas salinidades, impossibilitando a sobrevivência até das espécies mais resistentes. Na zona de manguezal, na primeira campanha, foram obtidas 116 testas $(5,1 \%$ de vivos; $0,0 \%$ de anômalos). De 10 espécies 4 se destacaram: Haplophragmoides wilberti; Ammonia beccarii; Quinqueloculina fusca e Q. venusta. Na segunda campanha, foram registradas apenas 143 testas $(0,70 \%$ de vivos; $0,0 \%$ de anomalias). De 10 espécies destacaram-se 3 espécies a saber: $H$. wilberti; Trochammina inflata e $Q$. fusca, sendo que, o aumento do número de testas, deve-se ao aumento da salinidade. Além disso, foi observado, apenas na primeira campanha do canal do rio Pardo que somente o chumbo (pontos 2, 3, 4, 5 e 6) apresentou valores acima dos limites estabelecidos pelos órgãos de referência (CONAMA - Brasil, 2012) e Canadian Council of Ministers of the Environment (CCME, 1998).

Palavras Chaves: Foraminíferos, Estuários, Metais pesados, Manguezal, Brasil

\section{ABSTRACT}

The associations of foraminifera, besides being abundant and presenting a wide geographical distribution, take advantage of the intrinsic peculiarities of these organisms to store in their tests characteristics of the places where they lived. In this context, the tests of these organisms were related to the trace-metal contents of the sediment of the estuarine system of the Jequitinhonha River, south coast of Bahia, aiming to evaluate whether the levels of these elements are affecting the microfauna. For the canal region, 281 foraminifera tests were obtained in the first campaign (4.98\% of the specimens were collected alive, and none of the tests were malformed) belonging to 10 species, of which Trochammina inflata; Haplophragmoides wilberti and Ammonia beccarii as major species. In the second sampling, there was no record of foraminifera, due to the low salinities, making it impossible the survival of even the most resistant species. In the mangrove area, in the first campaign, 116 tests $(5.1 \%$ alive, $\quad 0.0 \%$ anomalous) Among 10 species, 4 stand out: Haplophragmoides wilberti; Ammonia beccarii; Quinqueloculina fusca 
and $Q$. venusta. In the second campaign, only 143 specimens were registered $(0.70 \%$ alive, $0.0 \%$ anomalous $)$. Among 10 species 3 were stand out: H. wilberti; Trochammina inflata and $Q$. fusca, and the increase in the number of tests is due to the increase in salinity. In addition, it was observed only in the first campaign of the Pardo river channel that only lead (points 2, 3, 4, 5 and 6) presented values above the limits established by the reference institutions (CONAMA - Brazil, 2012) and Canadian Council of Ministers of the Environment (CCME, 1998).

Keywords: Foraminifera, Estuaries, Heavy Metals, Mangrove, Brazil

\section{INTRODUÇÃO}

Os estuários são caracterizados como ambientes costeiros situados na interface terramar, no qual funcionam como receptáculos de substâncias e produtos resultantes das interações humanas, as quais podem provocar as degradações das águas e dos ecossistemas (Teodoro et al., 2010). Consequentemente, a introdução direta ou indireta dessas interferências pelo homem, pode acarretar vários níveis de contaminação dos sistemas estuarinos, com graves efeitos aos recursos naturais, riscos a própria saúde humana, barreiras para as atividades pesqueiras, deterioração da qualidade da água e redução das suas belezas naturais (Silva \& Gomes, 2012).

Em paralelo a isso, está o manguezal, definido como ecossistema tropicais com vegetação intertidal dominante, que contribui significativamente para a sobrevivência de várias espécies de animais e vegetais, além de

\section{MATERIAIS E MÉTODOS}

Foram realizadas duas coletas de materiais em campo, a primeira campanha foi realizada de 25 a 27/11/2011 e a segunda campanha de 21 a 23/04/2012. Dessas coletas, foi obtido um conjunto amostral de 32 amostras (Figura 1), sendo 20 amostras de sedimento superficial de fundo (10 amostras em cada campanha) e 12 amostras do sedimento superficial nas zonas de manguezal (6 amostras em cada manguezal por campanha, totalizando 32 amostras) no estuário do rio Jequitinhonha. Para as coletas no canal estuarino foi utilizado um pegador de fundo do tipo van Veen (Figura 2A) e já as coletas do sedimento no manguezal foram feitas manualmente. Em ambos os casos, foram coletados dois grupos de amostras: um destinado ao estudo dos foraminíferos e outro às análises granulométricas e geoquímicas do sedimento. As amostras do primeiro grupo foram acondicionadas em frascos plásticos om tampa rosqueada e a elas foi adicionado o participar da produção primária da biomassa global (Bouillon et al., 2008). Contudo, em virtude do crescimento populacional estar voltado cada vez mais para as zonas de costa, o aporte de esgotos domésticos tornou-se uma das principais causas de poluição marinha (Lamparelli, 2007).

Dessa forma, estudos ambientais utilizando foraminíferos como bioindicadores têm sido cada vez mais frequentes, pois tais organismos apresentam alta sensibilidade para a variação dos fatores físico-químicos no meio ambiente, ciclos de vida curtos e de alta biodiversidade (Cosentino et al., 2013).

Assim sendo, o presente trabalho teve o objetivo de descrever as condições dominantes no canal estuarino e na zona de manguezal do rio Jequitinhonha, litoral sul do Estado da Bahia, através das características dos foraminíferos parálicos e dados geoquímicos do sedimento.

corante Rosa de Bengala para fixação dos indivíduos capturados vivos no ato da coleta, segundo o que preconiza a metodologia de Teodoro et al., (2009), sendo mantidas refrigeradas até o momento da análise (Figura 2B). As amostras do segundo grupo, foram armazenadas em recipientes de alumínio e congeladas até o seu processamento no laboratório.

Durantes as coletas registraram-se os parâmetros abióticos do canal estuarino e da água intersticial do manguezal através de sondas multiparamétricas.

Nos Laboratórios do Núcleo de Estudos Ambientais - NEA (Instituto de Geociências/Universidade Federal da Bahia), as amostras destinadas ao estudo dos foraminíferos foram lavadas sob água corrente e levadas à estufa a $60^{\circ} \mathrm{C}$ (Figuras $2 \mathrm{C}$ e 2D). Após a secagem, cerca de $3 \mathrm{~g}$ do sedimento foi vertido em béqueres, nos quais foi adicionado 
tricloroetileno para a separação das testas do sedimento por flotação (Donnici et al., 2012) (Figura 2E). Em seguida, o sobrenadante foi entornado em papel filtro e deixado na estufa por aproximadamente 5 minutos para secagem.
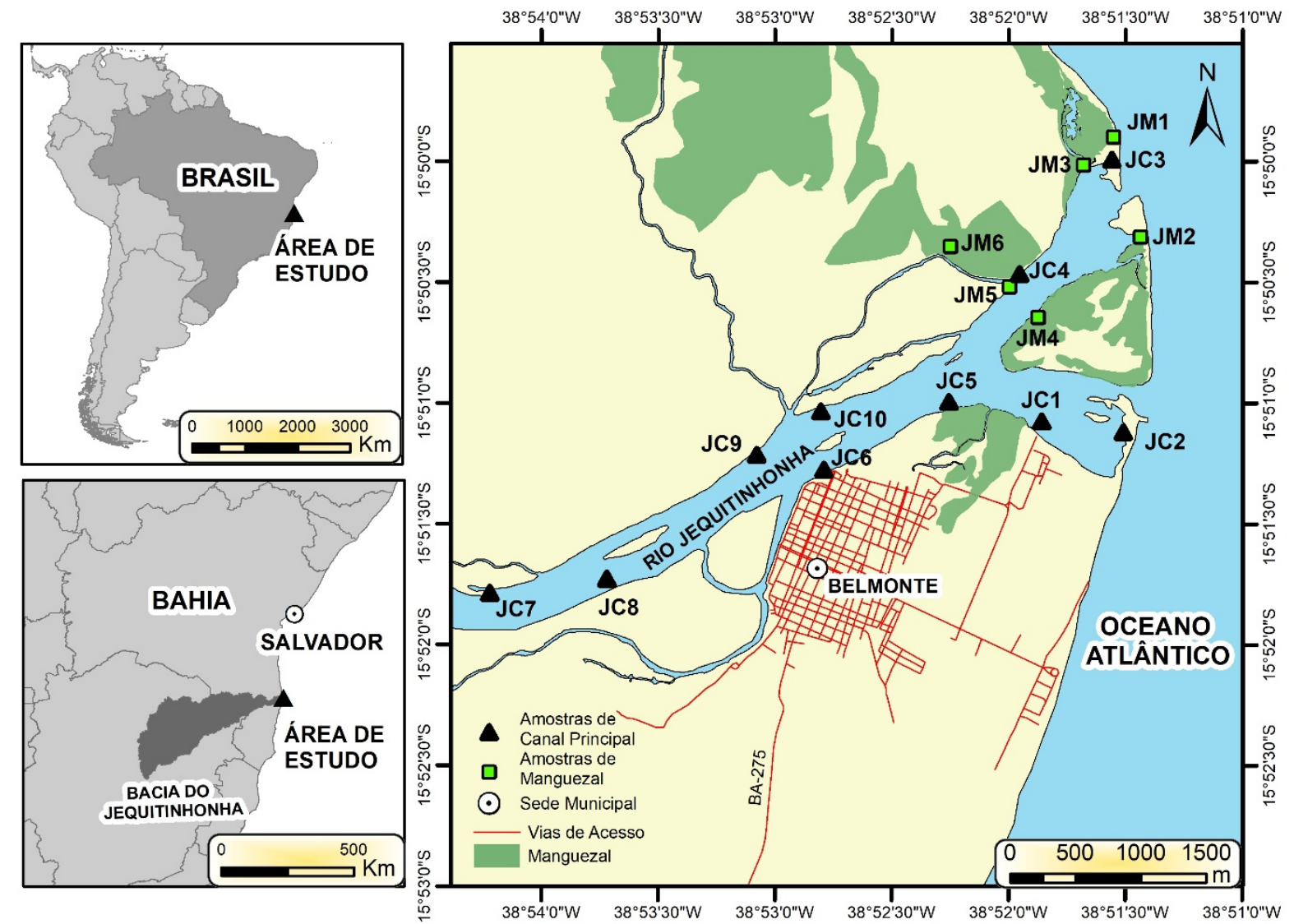

Figura 1

Mapa de localização do Município de Belmonte e dos pontos de amostragem no canal e manguezal

Elaboração: Rivaldo Vieira Santos

Fonte: Adaptado de Queiroz e Oliveira, (2013)

No Laboratório do Grupo de Estudos de Foraminíferos - LGEF, com o auxílio de estereomicroscópio, as testas foram retiradas do papel de filtro e fixadas com cola orgânica em lâminas para microfósseis. A identificação dos foraminíferos foi feita com base em literatura especializada e, durante esse procedimento, foram registradas informações relativas à sua coloração e ao estado de preservação (Machado et al., 2012) (Figura 2F). Também foi registrada, quando presente, a ocorrência de anomalias nas testas.

As análises das matrizes sedimentológicas e de nutrientes do canal e do manguezal do rio Jequitinhonha foram fornecidos por pesquisadores do NEA, de modo que os procedimentos para a realização dessas análises encontram-se descritos em Celino et al. (2014), Escobar et al. (2014) e Cruz (2012). Foram feitas análises descritivas dos resultados da fauna de foraminíferos, calculando-se a abundância relativa (Ab'saber et al., 1997) e adotadas as seguintes classes: principal (abundâncias $>5 \%$ ), acessória (4,9-1\%) e traço $(<1)$; e constante (ocorrências $>50 \%$ ), acessória $(49-25 \%)$ e acidental (<24\%) (Dajoz, 1983). Além disso, com auxílio do programa Primer 6.0 (CARR, 1996), foram calculados os índices de riqueza (índice de Margalef), equitatividade (índice de Pielou) diversidade (índice de Shannon-Wiener) (Clarke; Warwick, 2001).

Para comparação e análise das consequências dos teores de metais traços nos sedimentos na área em estudo, optou-se por utilizar os limites estabelecidos pela Resolução $\mathrm{N}^{\circ} 454 / 2012$ do CONAMA (BRASIL, 2012) e pelo Canadian Environmental Quality Guidelines (CCME, 1998).

Para identificar as associações entre os resultados obtidos, optou-se por utilizar o Coeficiente de Correlação Linear de Pearson. Essa análise de correlação exibe variáveis diretamente relacionadas por meio de uma correlação positiva ou variáveis inversamente relacionadas através de uma correlação negativa, que é definida por meio de um valor 
máximo igual a 1. Portanto, para as interpretações dos dados referentes aos foraminíferos, parâmetros físico-químicos, granulometria, nutrientes e metais adotou-se um valor de significância considerando $\mathrm{p}>$ 0,7 . Para o estabelecimento da correlação de
Pearson entre a distribuição dos foraminíferos e as variáveis ambientais, os resultados foram reunidos em uma matriz de dados, a partir da qual foram realizadas as análises de correlação no programa Microsoft Office Excel 2016.

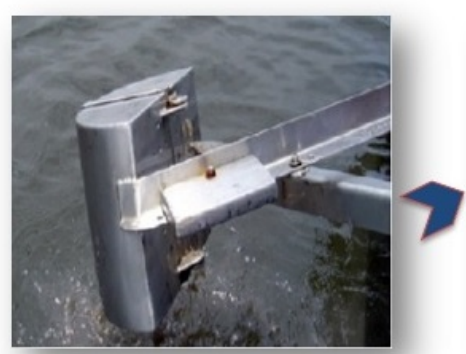

A. Van Veen

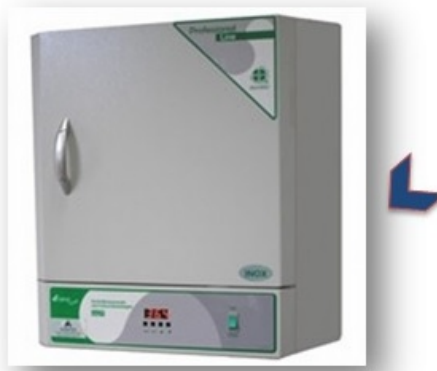

D. Secagem a $60^{\circ} \mathrm{C}$

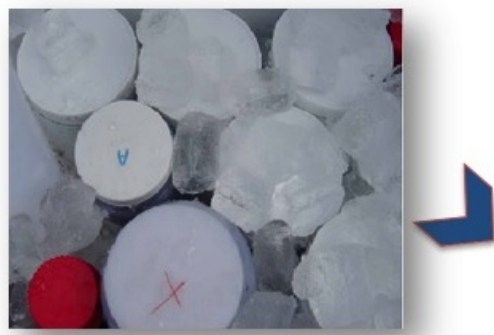

B. Sedimento armazenado com rosa de bengala

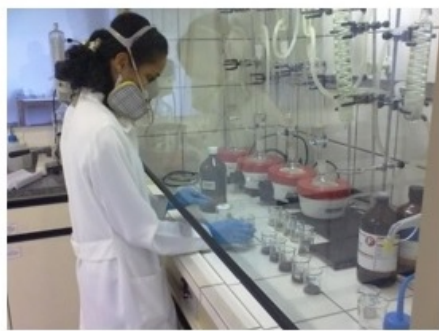

E. Flotação das testas de foraminíferos.

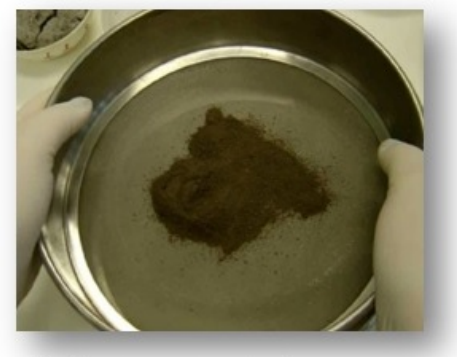

\section{Lavagem em água} corrente
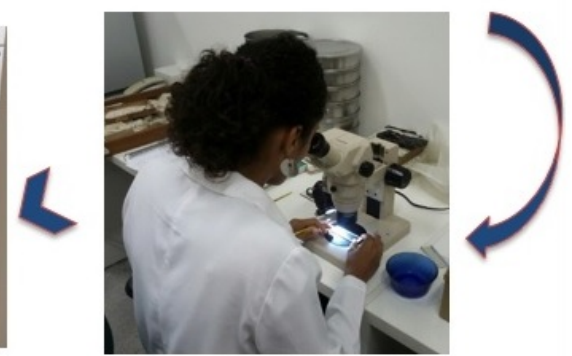

F. Identificação dos foraminíferos.

Figura 2

Procedimentos de coleta e análise laboratoriais das amostras

\section{RESULTADOS E DISCUSSÕES}

\subsection{CANAL ESTUARINO DO RIO JEQUITINHONHA: PARÂMETROS ABIÓTICOS}

Os resultados dos parâmetros físicoquímicos monitorados apresentaram-se em conformidade com os limites estabelecidos na Resolução 357, de 17 de março de 2005 do CONAMA (BRASIL, 2005), e com base nos dados de salinidade é possível observar valores inferiores a 0,5 dos pontos 2 ao 4 (período chuvoso - nov/2011) e nos pontos 1 e 3 a 6 (período seco - abr/2012), enquanto que valores de salinidade superior a 0,5 e inferior a 30,0 foram registrados apenas no ponto 2 estação seca (Figura 3). Além disso, dos locais amostrais os valores de salinidade registrados do ponto 05 ao 10 (período chuvoso) e do ponto 07 ao 10 (período seco) foi 0,0 ups. Constatou-se uma variação sazonal, na qual os registros de salinidade e temperatura foram menores na estação chuvosa (nov/2011) do que na estação seca (abr/2012) durante as campanhas amostrais (Figura 3). Um comportamento semelhante na variação de salinidade e temperatura também foi observada 146 por Jesus (2015), ao descrever características geoquímicas do estuário do rio Jequitinhonha nas estações seca (out/2012) e chuvosa (maio/2013).

Em ambas as campanhas, as águas estuarinas do canal do rio Jequitinhonha apresentaram-se levemente oxigenadas, (Figura 3), sendo que os menores valores registrados na estação seca podem estar relacionados à redução do volume de água e aumento da temperatura, como também pelo consumo de oxigênio por organismos durante a decomposição da matéria orgânica, perdas para atmosfera e nitrificação (CELINO et al., 2014). Valores semelhantes de OD também foram encontrados por Azevedo (2011), no trabalho de caracterização hidroquímica nos estuários de Santos.

$\mathrm{O} \mathrm{pH}$ do sedimento estava ligeiramente ácido a neutro, (Figura 3). No período chuvoso (nov/2011), quando se analisa a localização dos pontos de coleta no estuário, constata-se 
condições levemente mais ácidas a partir do ponto 7 , confirmando a expectativa de que os pontos próximos à foz sofrem maior influência do sistema marinho do que o ponto à montante, o qual está sob forte influência fluvial (VEIGA, 2010), condição que se repete no período seco (abr/2012). Características semelhantes acerca das variações de $\mathrm{pH}$, foram observadas também no trabalho de Bastos (2002) e Escobar et al. (2014), ambos no estuário do rio Una.

Com relação ao Eh do sedimento, no período chuvoso (nov/2011) foram obtidos valores negativos do ponto 01 ao 09, configurando-os como um ambiente redutor. Durante o período seco (abr/2012), todos os pontos mostraram valores negativos, característica de uma condição de ambiente redutor. A configuração de um sistema redutor pode estar relacionada a fatores como temperatura e matéria orgânica oriunda do manguezal e carreada durante a vazante do rio, sugerindo um ambiente rico em metano e sulfetos. O valor positivo de $\mathrm{Eh}$, apenas foi observado no ponto $10(18 \mathrm{mV})$ da estação chuvosa (nov/2011), caracterizando um ambiente oxidante. Tal dado é corroborado pelos elevados teores de oxigênio dissolvido durante a estação chuvosa, estando presente nas águas superficiais marinhas, devido ao fato dessas estarem em contato com a atmosfera oxidante (Figura 3 e Tabela 1). Os dados de Eh desse trabalho, assemelham-se aos valores encontrados por Celino et al. (2014), no estudo da geoquímica da água superficial e sedimento nos baixos cursos dos rios, Una, Pardo e Jequitinhonha.

Observou-se que em ambas campanhas amostrais, a fração granulométrica predominante foi areia fina, confirmando a expectativa de uma condição de menor energia hidrodinâmica no canal (Figura 3).

\subsection{FAUNA DE FORAMINÍFEROS}

No canal do rio Jequitinhonha, no período chuvoso (nov/2011), foram obtidos 281 indivíduos, dos quais, 14 estavam vivos. Não houve presença de espécies anômalas, sendo identificadas 5 espécies, destacando-se: Trochammina inflata (37,01\%), Haplophragmoides wilberti (22,79\%) e Ammonia beccarii (18,50\%) como as principais (Tabela 3). A presença da espécie $T$. inflata é indicativo de ambientes de baixa energia hidrodinâmica e águas salobras,
Os resultados obtidos para os nutrientes mostraram que em ambos os períodos hidrológicos, houve redução dos valores de fósforo assimilável $(2,5 \mathrm{mg} / \mathrm{L}$ a $168,8 \mathrm{mg} / \mathrm{L}$ na estação chuvosa e de $1,2 \mathrm{mg} / \mathrm{L}$ a $30,2 \mathrm{mg} / \mathrm{L}$ na estação seca). Tais dados sugerem que as concentrações de fósforo assimilável, podem ser resultantes de drenagens agrícolas das regiões próximas à montante, fato este que se torna ainda mais intenso durante o período chuvoso. Para os valores de nitrogênio total $(0,1 \mathrm{mg} / \mathrm{L}$ a $1,1 \mathrm{mg} / \mathrm{L}$ no período chuvoso e $0,1 \mathrm{mg} / \mathrm{L}$ a $2,6 \mathrm{mg} / \mathrm{L}$ no período seco), observou-se um aumento em ambas estações de coletas (Tabela 1)

Os valores de nitrogênio total encontrado em ambas campanhas foram considerados baixos, sugerindo não provir de ações antrópicas (i.e. agrotóxicos, pesticidas e/ou dejetos domésticos) e sim de processos naturais como, por exemplo o consumo de fitoplâncton (CARVALHO et al., 2010).

As concentrações de $\mathrm{Ni}, \mathrm{Cr}, \mathrm{Cu}, \mathrm{Pb}$ e $\mathrm{Cd}$ (período chuvoso/2011) no sedimento são baixas quando comparadas aos limites do CONAMA (BRASIL, 2012) e do CCME (1998) e, por isso, não devem estar causando efeitos adversos à biota do canal do rio Jequitinhonha (Tabela 2). Entretanto, estas normatizações não estabelecem limites para $\mathrm{Mn}$ e $\mathrm{Fe}$, o que impossibilita avaliar o efeito destes elementos. Por outro lado, os resultados da concentração de $\mathrm{Cd}$ nos pontos 3 e 4 (13,48 mg. $\mathrm{Kg}^{-1}$ e $0,46 \mathrm{mg} . \mathrm{Kg}^{-1}$ respectivamente) da primeira campanha e em todos os pontos da segunda campanha $\left(0,45 \mathrm{mg} \cdot \mathrm{Kg}^{-1}\right.$ ponto 3 maior valor) encontram-se acima dos limites dos órgãos de referência. Tais informações, sugerem que haja uma fonte pontual de contaminação por cádmio no ponto 3 proveniente de material marinho (fosfato marinho e sistemas aquáticos).

enquanto que $H$. wilberti, distribui-se preferencialmente em substratos de granulometria fina e rico em nutriente. Já a espécie $A$. beccarii é a mais tolerante às grandes mudanças na temperatura e salinidade, além de apresentar preferência por sedimentação com aporte de nutrientes, corroborando com os estudos ecológicos, através de foraminíferos bentônicos realizados por Murray (2006). 
Salinidade - Canal

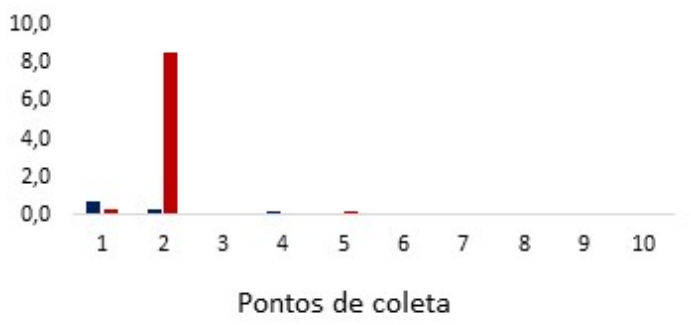

Oxigênio dissolvido (O.D.) - Canal

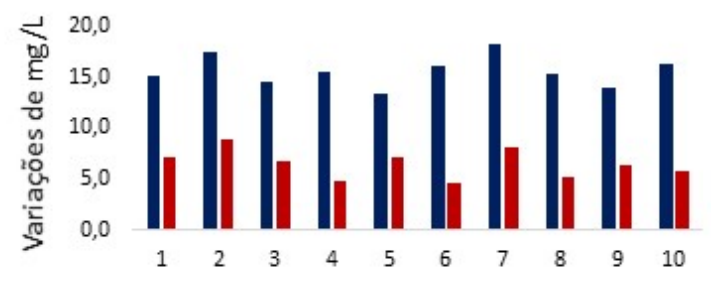

Pontos de coleta

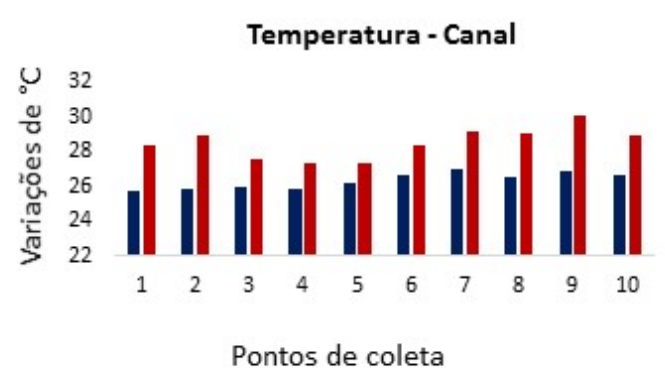

pH - Canal

10,0

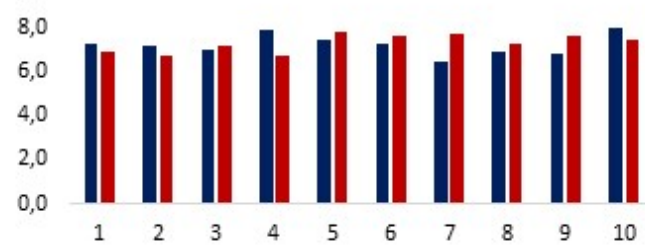

Pontos de coleta

\section{Eh - Canal}

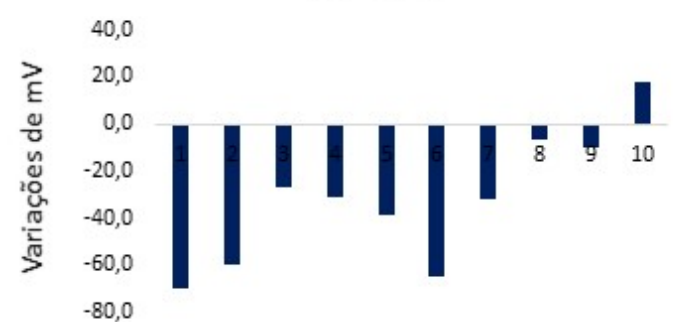

Pontos de coleta

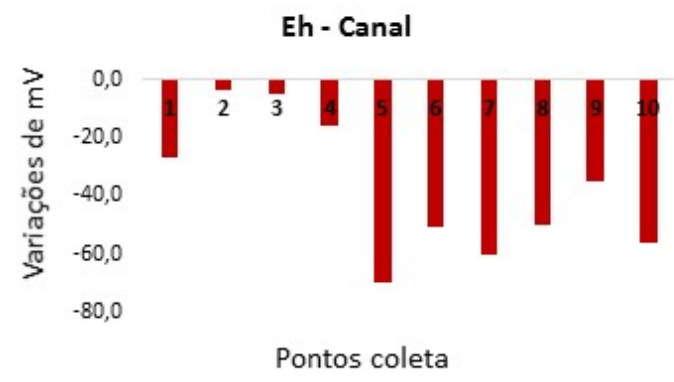

Frações granulométricas - Canal

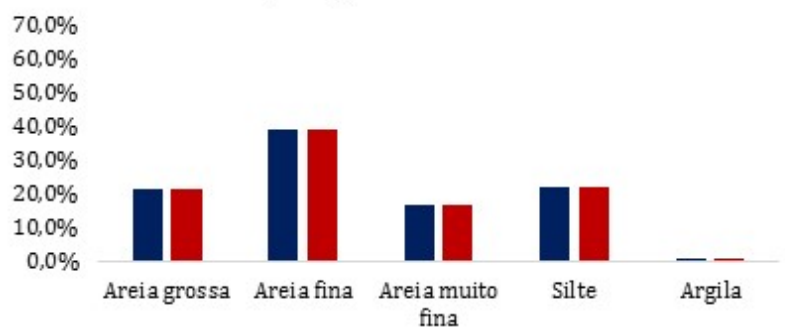

Figura 3

Valores dos parâmetros físico-químicos, salinidade, temperatura, oxigênio dissolvido (O.D.) da água e potencial hidrogeniônico $(\mathrm{pH})$, potencial de oxirredução (Eh) e frações granulométricas do sedimento do canal estuarino do rio Jequitinhonha, relativas às campanhas de nov/2011 (período chuvoso) e abr/2012 (período seco). 
No período seco, a não ocorrência de foraminíferos se deve aos baixos valores de salinidade, os quais impossibilitaram a sobrevivência até mesmo das espécies mais resistentes (Gómes; Bernal, 2011) (Tabelas 1 e 3)

$\mathrm{Na}$ estação chuvosa, os valores de riqueza variaram de 0,5 a 1,1 ; os de equitividade foram todos acima de 0,5 , sugerindo a inexistência de dominância, como observado em estudos estatísticos com comunidades marinhas, realizados por Clarke e Warwick (2001). Os valores de diversidade oscilaram de 0,3 a 1,3 (Tabela 3), sendo estes considerados baixos quando comparados com aqueles obtidos por Gomes (2010) no estuário do rio Jacuípe-BA (1,0 a 4,4); por Teodoro (2009 e 2010) no Canal de São Sebastião, SP $(0,3$ a 2,8) e Araçá $(2,4$ a 2,9), também próximo ao Canal de São Sebastião-SP. Já na estação seca, a inexistência de registro de foraminíferos inviabilizou o cálculo dos índices de riqueza, equitatividade e diversidade.

No período chuvoso, a maioria das testas exibiu colorações brancas ou incolores $(63,70 \%$ - Figura 4) ou amarelas $(25,62 \%$ Figura 4). Quanto ao desgaste, (44,48\% Figura 4) das testas estavam normais, mas $(29,89 \%$ - Figura 4) apresentaram sinais de abrasão.

O predomínio de testas brancas é indicativo de uma taxa de deposição muito rápida, com muito material novo sendo adicionado ao sedimento, principalmente durante a estação seca, o que é corroborado pelo domínio de testas normais. Entretanto, o fato da abrasão ser o tipo de desgaste mais frequente, evidencia um ambiente de alta energia (Machado et al., 2012), contrariando os dados granulométricos que denotam um ambiente de baixa energia para o canal estuarino.

Durante a estação chuvosa (nov/2011), a distribuição dos foraminíferos vivos foi positivamente correlacionada à fração argila (Tabela 4), indicando uma preferência destes organismos pela sedimentação fina, possivelmente, devido ao fato destas frações possuírem maior conteúdo orgânico.

$\mathrm{Na}$ estação seca (abr/2012), a ausência de foraminíferos pode ser atribuída à redução da salinidade, o que é um fator limitante para o estabelecimento das comunidades de foraminíferos bentônicos (Laut et al., 2014). Além disso, as correlações positivas entre nitrogênio e metais pesados, sugerindo o aporte de uma fonte antrópica de metais pesados no sedimento do rio Jequitinhonha (Escobar et al., 2014) (Tabela 4), podem ser mais um fator limitante à presença destes organismos no ambiente.

As testas de foraminíferos mortos são negativamente influenciadas pelo Eh, visto que os valores de Eh registrados em todos os pontos de ambas estações, foram negativos com exceção do ponto 10 no período chuvoso. Além disso, valores de Eh entre -50 e -150 $\mathrm{mV}$, semelhantes aos que foram encontrados nos pontos 01,02 e 06 (período chuvoso) e nos pontos $05,06,07,08$ e 10 (período seco) são geralmente indicativo de ambientes com sinais de hipóxia (Sutherland et al., 2007).

\subsection{ZONA DE MANGUEZAL DO RIO JEQUITINHONHA: PARÂMETROS ABIÓTICOS}

Com relação às águas intersticiais das zonas de manguezal do rio Jequitinhonha, durante o período chuvoso (nov/2011), foi possível registrar o valor de salinidade apenas no ponto 01 (2,0 ups). Apesar disto, constatou-se que os, valores de salinidade e temperatura foram maiores no período seco, provavelmente devido à redução do volume de água (Azevedo et al., 2011) (Figura 5). Durante a baixa precipitação pluvial, ocorre o domínio das correntes de marés fazendo com que as águas salgadas penetrem no estuário, tornando as águas mais salinas, consequentemente a temperatura também aumenta, influenciada pela evaporação no período seco (Berrêdo et al., 2008).

Conforme esperado para zonas de manguezal, o sedimento estava ligeiramente ácido $(\mathrm{pH} \mathrm{6,4} \mathrm{a}$ 6,9 na estação chuvosa) e levemente ácido a neutro ( 6,1 a 7,4 na estação seca) (Figura 6), já que a decomposição das folhas do mangue faz com que o solo seja rico em compostos ácidos, apresentando oscilações de $\mathrm{pH}$ entre 4,8 e 8,8 (Paula Filho et al., 2012).

Os valores de $\mathrm{Eh}$ do sedimento foram negativos nos pontos 1, 4 e 6 , caracterizando-os como um ambiente redutor, enquanto que nos pontos 2, 3 e 5 foram positivos, evidenciando um ambiente oxidante. Todavia, na estação seca, os pontos 2 e 3 permaneceram com valores negativos, ao passo que o ponto 6 passou a apresentar valor positivo, sugerindo uma extensão da condição oxidante durante o período seco (Figura 5). O caráter redutor do solo deve-se ao carreamento da matéria orgânica oriunda do manguezal durante vazante do rio (Celino et al., 2014), sendo, por isso, mais prevalente durante o período chuvoso. 


\section{Coloração das carapaças - Canal}

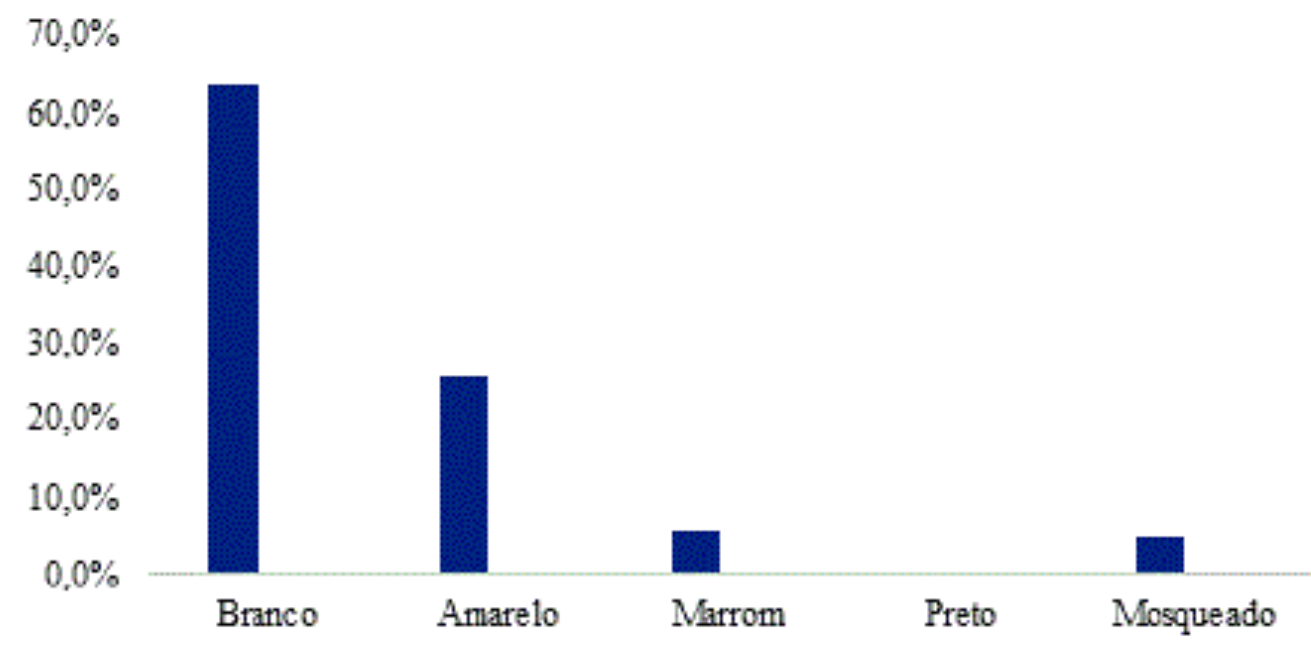

\section{Desgastes das carapaças - Canal}

$70,0 \%$

$60,0 \%$

$50,0 \%$

$40,0 \%$

$30,0 \%$

$20,0 \%$

$10,0 \%$

$0,0 \%$
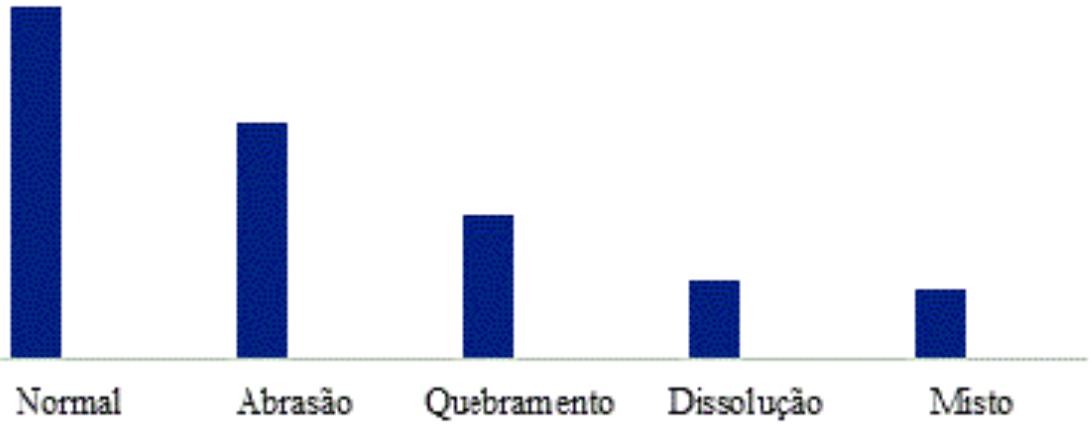

Figura 4

Percentuais dos tipos de coloração e desgaste dos foraminíferos no canal estuarino do rio Jequitinhonha, referente ao período chuvoso (nov/2011)

Houve predomínio das frações areia muito fina e silte em ambos períodos amostrais, corroborando com a condição de um ambiente deposicional de baixa energia hidrodinâmica, característico das zonas de manguezal (Figura 6).

De modo geral, os teores de nitrogênio total e fósforo assimilável foram maiores nos pontos situados próximos a jusante (pontos $01,02,03$ e 04 - Figura 5), evidenciando contribuições das águas marinhas que tendem a diluir suas concentrações na foz, situação esta que se torna mais intensa no período chuvoso, como também observado por Martins et al. (2011) em estudos de distribuição de fósforo no sedimento do estuário do rio Jaguaribe, NE do Brasil. 


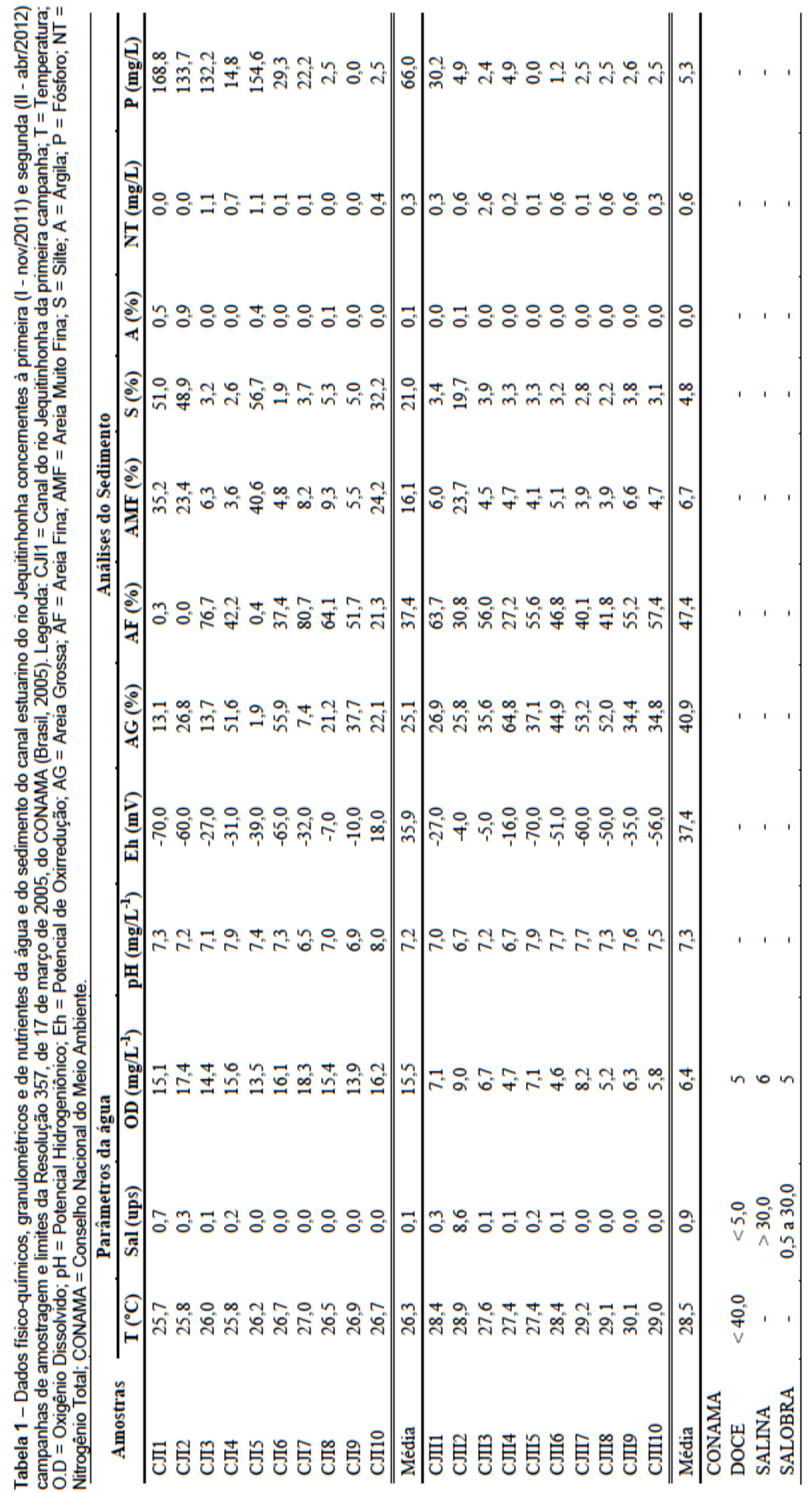


Tabela 2 - Concentrações de metais (em mg. Kg -1) no sedimento do canal estuarino do rio Jequitinhonha, concernentes à primeira (I - nov/2011) e segunda (II - abr/2012) campanhas de amostragem e valores de referência da Resolução do CONAMA No 454/2012 (Brasil, 2012) e do Canadian Environmental Quality Guidelines (CCME, 1998). Legenda: LD = Limite de Detecção; N1 e ISQG= limiar abaixo do qual há menor probabilidade de efeitos adversos à biota; N2 e PEL= limiar acima do qual há maior probabilidade de efeitos adversos à biota; n.d. = não determinado.

\begin{tabular}{|c|c|c|c|c|c|c|c|}
\hline Amostras & $\mathrm{Ni}$ & Mn & $\mathbf{F e}$ & $\mathrm{Cr}$ & $\mathrm{Cu}$ & $\mathbf{P b}$ & Cd \\
\hline CJI1 & 0,010 & 19,98 & 694 & 0,02 & 0,01 & 0,80 & 0,00 \\
\hline CJI2 & 0,010 & 11,37 & 2313 & 0,40 & 0,16 & 1,11 & 0,01 \\
\hline CJI3 & 0,010 & 330,03 & 327 & 0,05 & 0,01 & 9,24 & 13,48 \\
\hline CJI4 & 13,17 & 198,89 & 16350 & 19,60 & 7,31 & 10,50 & 0,46 \\
\hline CJI5 & 5,51 & 326,49 & 20488 & 22,86 & 8,00 & 13,06 & 0,04 \\
\hline CJI6 & 0,010 & 55,10 & 935 & 1,12 & 0,04 & 0,83 & 0,00 \\
\hline CJI7 & 4,14 & 23,27 & 2632 & 2,05 & 0,80 & 2,06 & 0,00 \\
\hline CJI8 & 0,010 & 53,14 & 832 & 1,34 & 0,01 & 0,69 & 0,01 \\
\hline CJI9 & 0,010 & 36,58 & 969 & 0,05 & 0,01 & 0,32 & 0,00 \\
\hline CJI10 & 7,88 & 162,52 & 6885 & 9,93 & 1,08 & 3,71 & 0,01 \\
\hline Média & 3,07 & 121,73 & 5242,50 & 5,74 & 1,74 & 4,23 & 1,40 \\
\hline CJII1 & 0,32 & 20,48 & 420 & 0,47 & 0,23 & 0,01 & 0,38 \\
\hline CJII2 & 0,62 & 26,59 & 986 & 1,19 & 0,37 & 0,52 & 0,38 \\
\hline CJII3 & 2,19 & 110,1 & 3628 & 5,41 & 1,80 & 1,86 & 0,45 \\
\hline CJII4 & 0,43 & 14,64 & 660 & 0,56 & 0,32 & 0,61 & 0,43 \\
\hline CJII5 & 0,22 & 20,46 & 328 & 0,21 & 0,08 & 0,01 & 0,38 \\
\hline CJII6 & 0,06 & 14,72 & 407 & 0,24 & 0,07 & 0,90 & 0,42 \\
\hline CJII7 & 0,32 & 15,84 & 544 & 0,60 & 0,14 & 0,95 & 0,39 \\
\hline CJII8 & 0,06 & 19,36 & 646 & 0,54 & 0,15 & 0,01 & 0,43 \\
\hline CJII9 & 0,07 & 20,19 & 344 & 0,05 & 0,23 & 0,25 & 0,41 \\
\hline CJII10 & 0,15 & 23,02 & 436 & 0,51 & 0,06 & 0,01 & 0,38 \\
\hline Média & 0,44 & 28,54 & 839,90 & 0,97 & 0,34 & 0,51 & 0,40 \\
\hline LD & 0,00415 & 0,00111 & 0,02586 & 0,01632 & 0,00336 & 1,49 & 0,00095 \\
\hline CONAMA N1 & 20,9 & n.d. & n.d. & 81 & 34 & 46,7 & 1,2 \\
\hline CONAMA N2 & 51,6 & n.d. & n.d. & 370 & 270 & 218 & 7,2 \\
\hline CEQG ISQG & n.d. & n.d. & n.d. & 52,3 & 18,7 & 30,2 & 0,7 \\
\hline CEQG PEL & n.d. & n.d. & n.d. & 160 & 108 & 112 & 4,21 \\
\hline
\end{tabular}

As concentrações de $\mathrm{Ni}, \mathrm{Cr}$ e $\mathrm{Zn}$ foram baixas quando comparadas aos limites da Resolução do CONAMA N $\mathrm{N}^{\mathrm{o}} 454 / 2012$ (BRASIL, 2012) e do Canadian Environmental Quality Guidelines (CCME, 1998), constatando-se que tais metais não devem estar causando efeitos adversos à biota do canal do rio Jequitinhonha (Tabela 6). Por outro lado, o $\mathrm{Pb}$ nos pontos 2, 3, 4, 5 e 6 (período chuvoso) apresentou teores acima dos limites estabelecidos pelos órgãos (Tabela 6), o que pode estar relacionado à drenagem de

\subsection{FAUNA DE FORAMINÍFEROS}

No período chuvoso, foram obtidos 116 indivíduos do quais apenas 6 estavam vivos. Não foram encontrados testas no ponto $6 \mathrm{e}$, apesar das elevadas concentrações de metais traços, não houve registro de testas anômalas em nenhum dos pontos.

Nessa amostragem, foram identificadas 10 espécies, destacando-se Haplophragmoides wilberti (37,1\%), Ammonia beccarii (32,8\%), Quinqueloculina fusca $(12,1 \%)$ e Q. venusta fertilizantes e compostos químicos utilizados no desenvolvimento agrícola (Zourarah et al., 2009). Já as elevadas concentrações dos metais $\mathrm{Cu}$ (ponto 2), $\mathrm{Pb}$ (ponto 1) e $\mathrm{Cd}$ (ponto 2) no período seco devem-se à redução da vazão aumentando as concentrações na água e, consequentemente, possibilitando suas deposições nos sedimentos. Estas normatizações não estabelecem limites para $\mathrm{Mn}$ e $\mathrm{Fe}$, o que impossibilita avaliar o efeito destes elementos.

(5,2\%) (Tabela 7). A ocorrência de A. beccarii deve-se ao fato desta ser mais tolerante à grandes mudanças de salinidade e temperatura; e à contaminação por metais traços, como também exposto por Martins et al. (2010) em seus estudos sobre os efeitos ecológicos de metais pesados em assembleias de foraminíferos bentônicos dos canais de Aveiro, Portugal. 


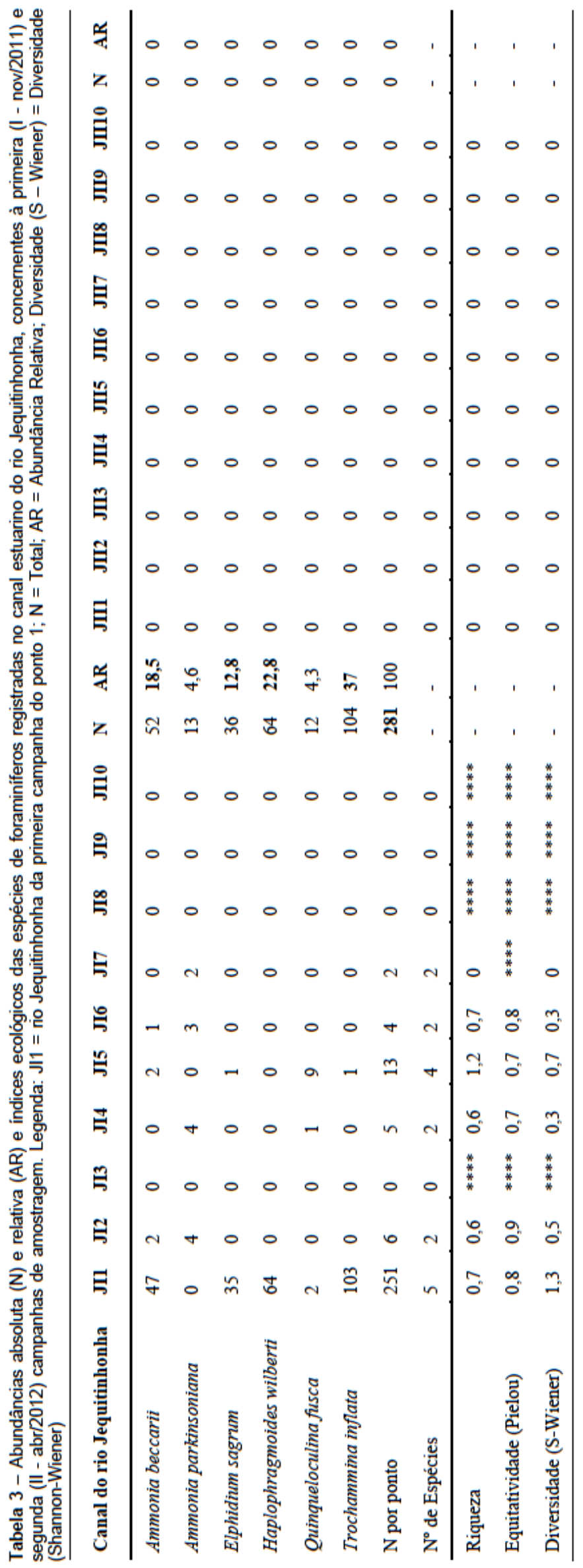




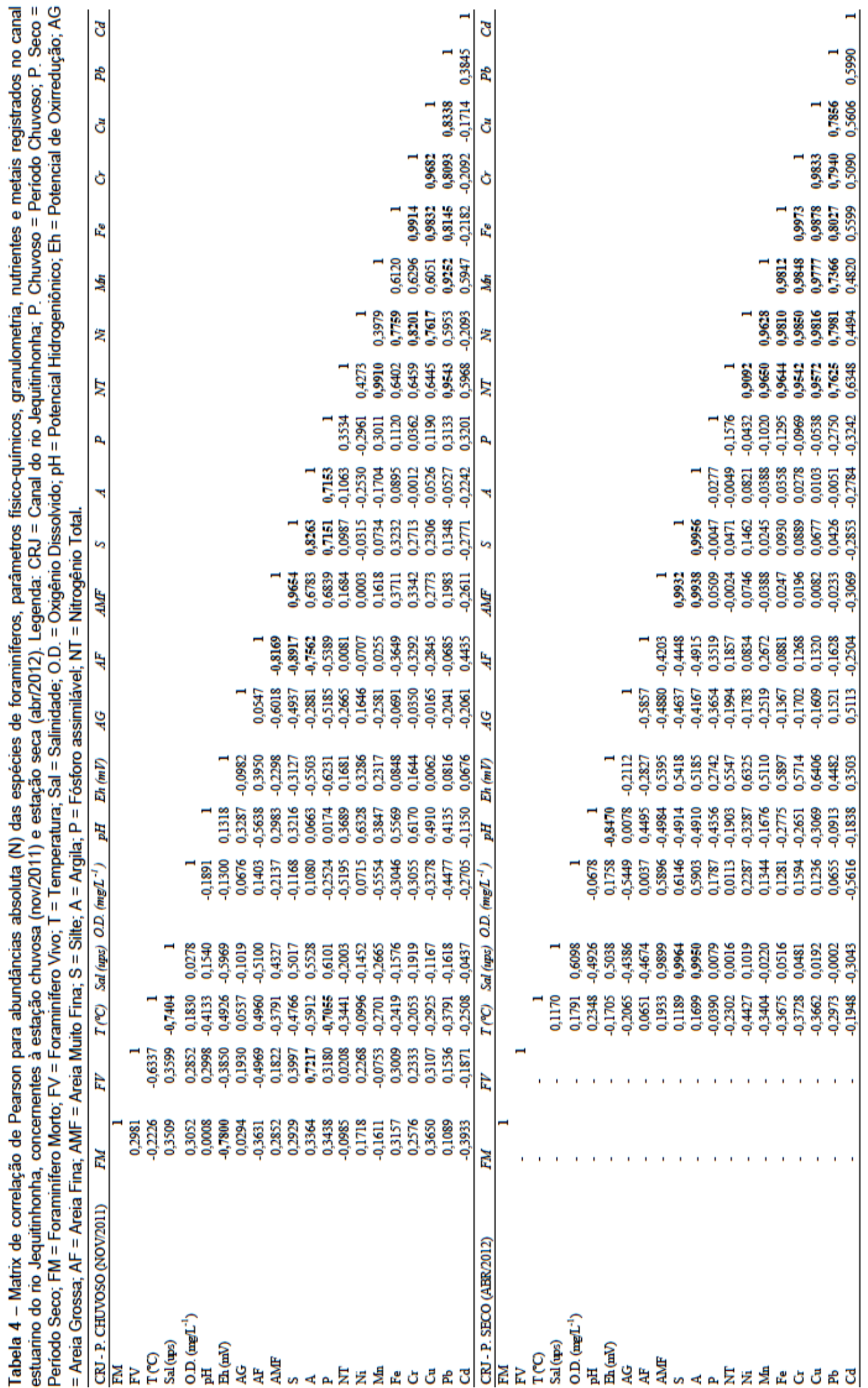



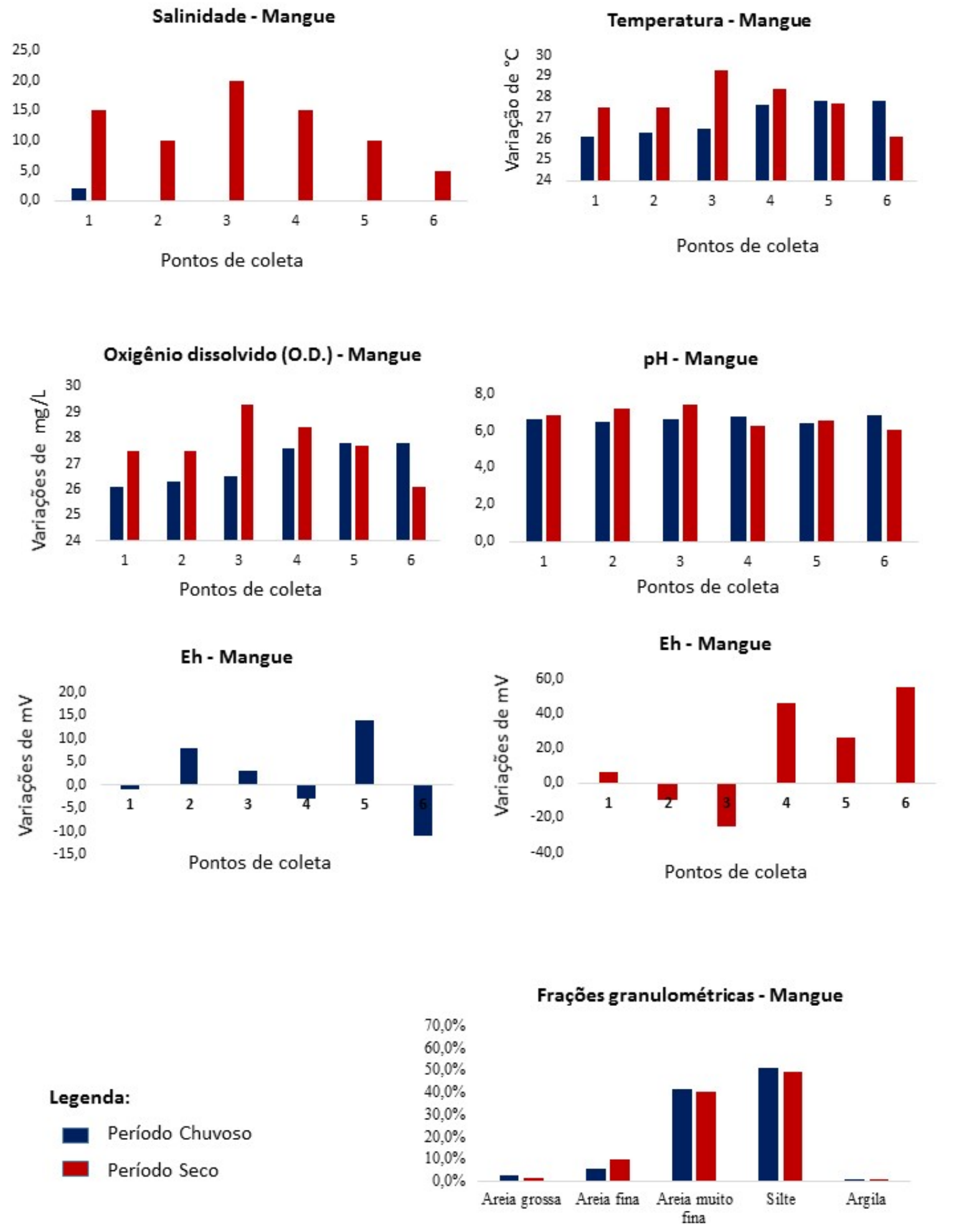

Figura 5

Valores dos parâmetros físico-químicos, salinidade, temperatura, das águas intersticiais e potencial hidrogeniônico (pH), potencial de oxirredução (Eh) e frações granulométricas do sedimento da Zona de Manguezal do rio Jequitinhonha, relativas às campanhas de nov/2011 (período chuvoso) e abr/2012 (período seco). 


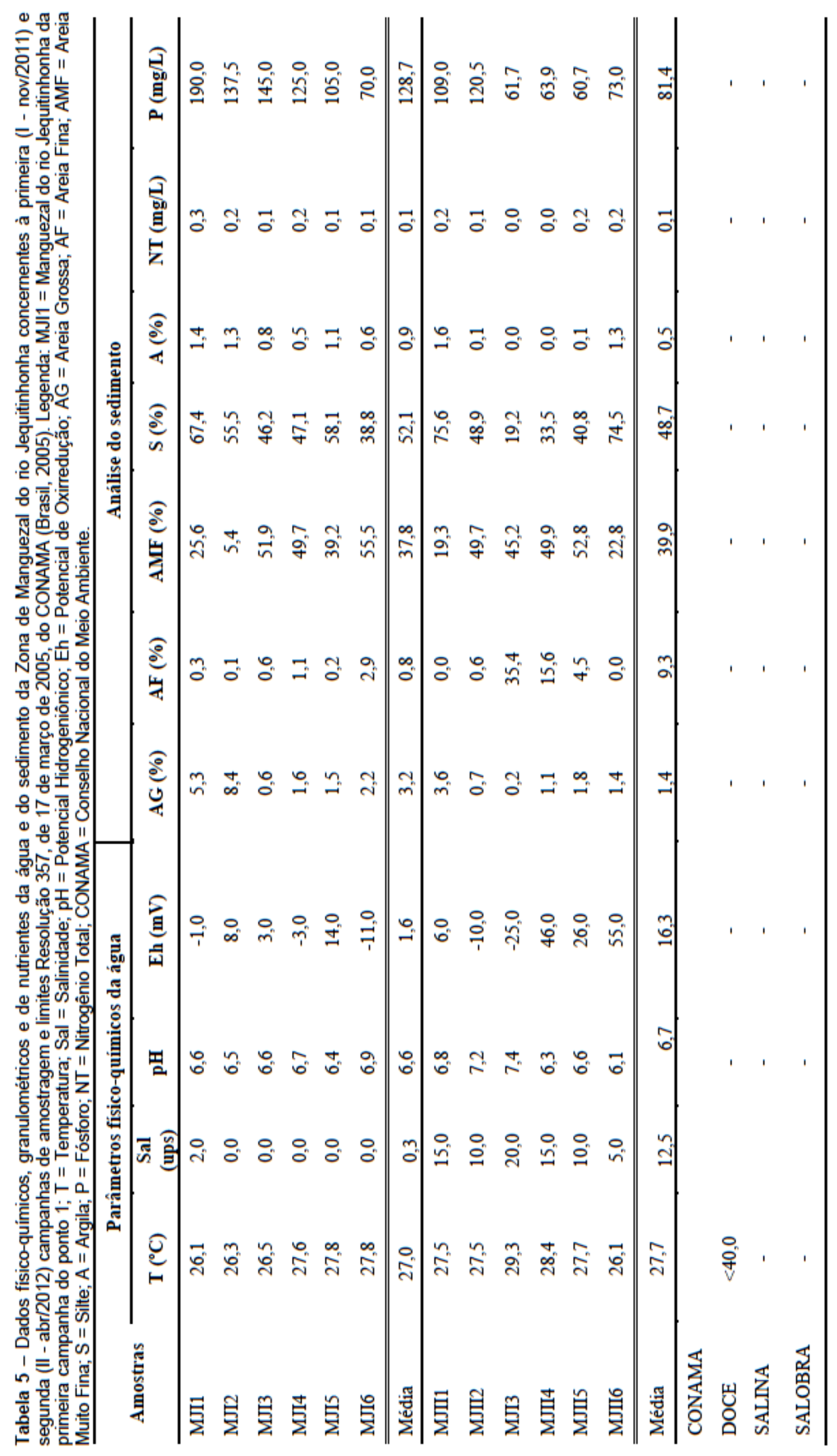


Tabela 6 - Concentrações de metais (mg. Kg -1) no sedimento da Zona de Manguezal do rio Jequitinhonha, concernentes à primeira (I - nov/2011) e segunda (II - abr/2012) campanhas de amostragem e valores de referência da Resolução do CONAMA No 454/2012 (Brasil, 2012) e do Canadian Environmental Quality Guidelines (CCME, 1998). Legenda: LD = Limite de Detecção; N1 e ISQG= limiar abaixo do qual há menor probabilidade de efeitos adversos à biota; N2 e PEL= limiar acima do qual há maior probabilidade de efeitos adversos à biota; n.d. = não determinado.

\begin{tabular}{|c|c|c|c|c|c|c|c|c|}
\hline Amostras & $\mathrm{Ni}$ & Mn & $\mathbf{F e}$ & $\mathrm{Cr}$ & $\mathrm{Zn}$ & $\mathrm{Cu}$ & $\mathbf{P b}$ & Cd \\
\hline MJI1 & 8,91 & 65,58 & 13769,9 & 24,99 & 29,15 & 11,46 & 48,16 & 0,54 \\
\hline MJI2 & 8,54 & 83,49 & 12480,5 & 20,99 & 27,52 & 8,87 & 33,39 & 0,38 \\
\hline MJI3 & 8,47 & 133,34 & 13524,7 & 22,02 & 29,01 & 8 & 36,5 & 0,49 \\
\hline MJI4 & 9,49 & 73,04 & 12154,2 & 22,2 & 29,42 & 9,9 & 34,77 & 0,43 \\
\hline MJI5 & 6,88 & 46,73 & 8312,48 & 16,22 & 22,48 & 7,68 & 41,76 & 0,27 \\
\hline MJI6 & 5,96 & 36,84 & 6722,17 & 12,71 & 18,33 & 6,18 & 33,4 & 0,23 \\
\hline Média & 8,04 & 73,17 & 11160,66 & 19,855 & 25,98 & 8,68 & 37,99 & 0,39 \\
\hline MJII1 & 9,14 & 67,43 & 14254,7 & 29,15 & 38,88 & 13,46 & 32,75 & 0,55 \\
\hline MJII2 & 11,57 & 275,57 & 17617,1 & 27,52 & 48,68 & 20,44 & 48,11 & 0,77 \\
\hline MJII3 & 6,61 & 133,92 & 9398,81 & 36,78 & 27,76 & 7,21 & 26,12 & 0,36 \\
\hline MJII4 & 8,04 & 51,39 & 9446,2 & 18,34 & 32,95 & 10,16 & 54,27 & 0,29 \\
\hline MJII5 & 10,17 & 70,57 & 12746,8 & 18,32 & 38,33 & 12,28 & 38,57 & 0,45 \\
\hline MJII6 & 11,19 & 54,51 & 14534,5 & 31,88 & 38,46 & 16,82 & 43,53 & 0,59 \\
\hline Média & 9,45 & 108,89 & 12999,69 & 26,99 & 37,51 & 13,39 & 40,55 & 0,50 \\
\hline LD & 0,00415 & 0,00111 & 0,02586 & 0,01632 & 0,00651 & 0,00336 & 1,49 & 0,00095 \\
\hline CONAMA N1 & 20,90 & n.d. & n.d. & 81 & 150 & 34 & 46,7 & 1,2 \\
\hline CONAMA N2 & 51,60 & n.d. & n.d. & 370 & 410 & 270 & 218 & 7,2 \\
\hline CEQG ISQG & n.d. & n.d. & n.d. & 52,3 & 124 & 18,7 & 30,2 & 0,7 \\
\hline CEQG PEL & n.d. & n.d. & n.d. & 160 & 271 & 108 & 112 & 4,2 \\
\hline
\end{tabular}

No período seco $(\mathrm{abr} / 2012)$, foram obtidos 143 foraminíferos, sendo que apenas 10 estavam vivos, e não houve registro de testas anômalas. Foram identificadas 10 espécies, sendo que $H$. wilberti $(55,9 \%)$, Trochammina inflata $(19,6 \%)$ e $Q$. fusca $(7,0 \%)$ foram as principais (Tabela 7).

$\mathrm{O}$ aumento do número de foraminíferos pode ser atribuído ao aumento significativo da salinidade, o mesmo foi verificado por Martins et al. (2010). Além disso, o predomínio da espécie $H$. wilberti, em ambos os períodos amostrais, deve-se à presença de ambientes compostos de sedimentação fina e ricos em nutrientes, típico de regiões de manguezal (Gómes; Bernal, 2011; Machado et al., 2012). Já o gênero Quinqueloculina é típico de ambientes arenosos e lamosos, corroborando com o elevado número de testas durante a primeira campanha, a qual apresentou predomínio de areia muito fina e silte (Lemos Júnior, 2011).

Os valores de riqueza $(0,4$ a 2,0 no período chuvoso e 0,5 a 1,7 na estação seca) e de diversidade $(0,3$ a 1,4 na primeira campanha e 0,3 a 1,3 na segunda) foram maiores na primeira amostragem (Tabela 7), mas os índices de equitatividade estiveram acima 0,5 em ambas as campanhas, indicando ausência de dominância (Clarke \& Warwick, 2001). Apesar disto, os valores de diversidade foram considerados elevados quando comparados com os dados obtidos por Semensatto-Jr et al.
(2009) em um ambiente de manguezal situado ao norte da Ilha do Cardoso, Baia de CananéiaIguape-SP $(0,2$ a 0,6$)$.

O domínio de testas brancas ou incolores $(72,27 \%$ - Figura 6$)$ no período chuvoso pode ser atribuído a uma adição rápida de testas novas ao sedimento, conforme verificado por Machado et al., (2012) em estudos tafonômicos com assembleias de foraminíferos, no Município de Conde, Bahia (Figura 6). Entretanto, houve também um alto percentual de testas abrasadas $(50,00 \%$ Figura 6), as quais indicam condições de alta energia associada a uma redução na taxa de sedimentação (Lemos Júnior, 2011). Considerando-se que a maioria dos espécimes abrasados era da espécie $A$. beccarii e estas também podem ser encontradas no canal estuarino do rio Jequitinhonha (Figura $4 \mathrm{e}$ Tabela 3), é possível inferir que algumas das testas tenham sido transportadas para dentro do manguezal devido a velocidade das correntes na região, conforme observado por Rodrigues et al. (2003), em estudos semelhantes realizados no canal de Bertioga - SP. Já na segunda campanha, houve predomínio de testas marrons $(60,00 \%$ - Figura 6$)$, sugerindo uma lenta taxa de sedimentação, causada por um intenso, porém não rápido, trabalho de erosão ou de bioturbadores (Machado et al., 2012), o que é confirmado pelo predomínio de testas normais (40,60\% - Figura 6$)$. 


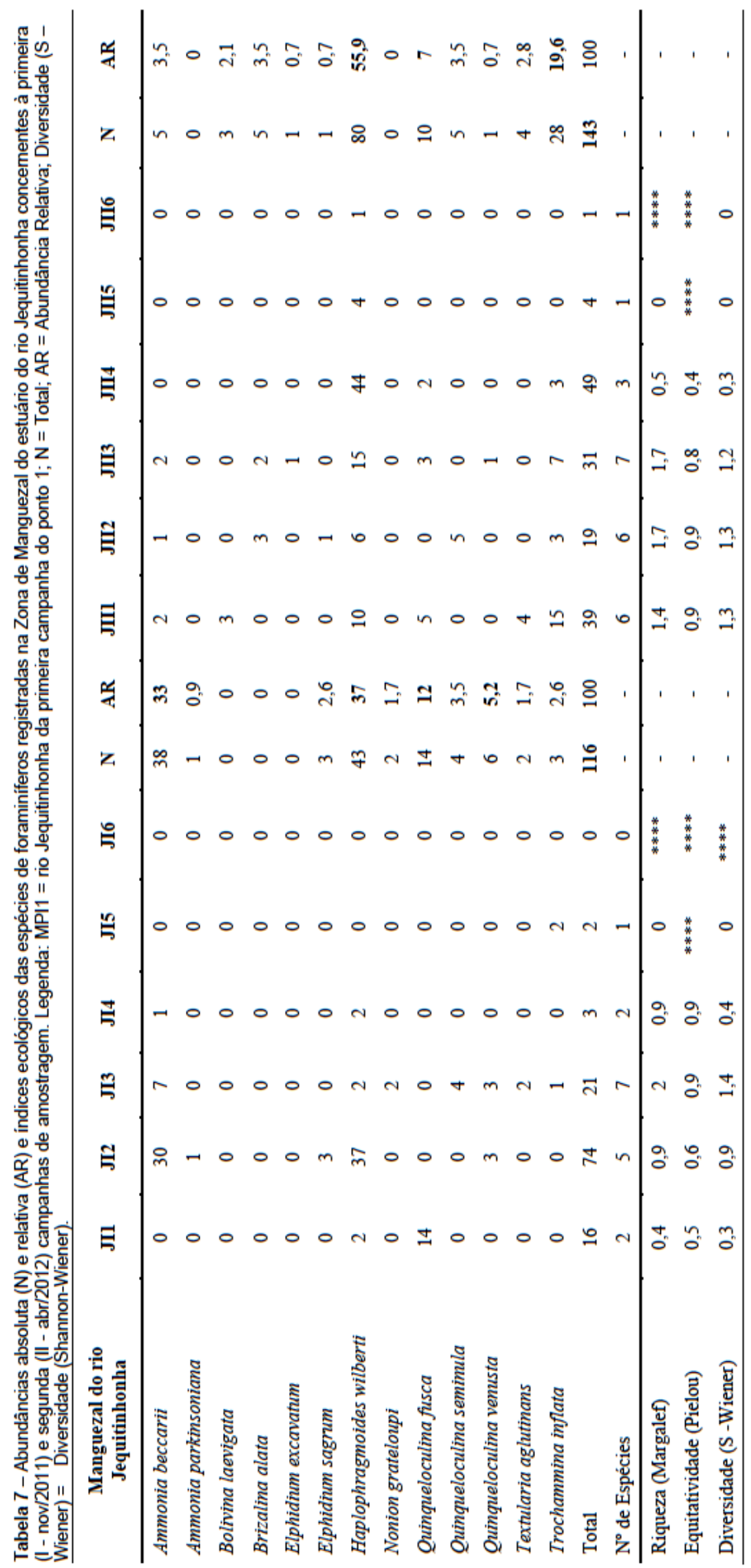



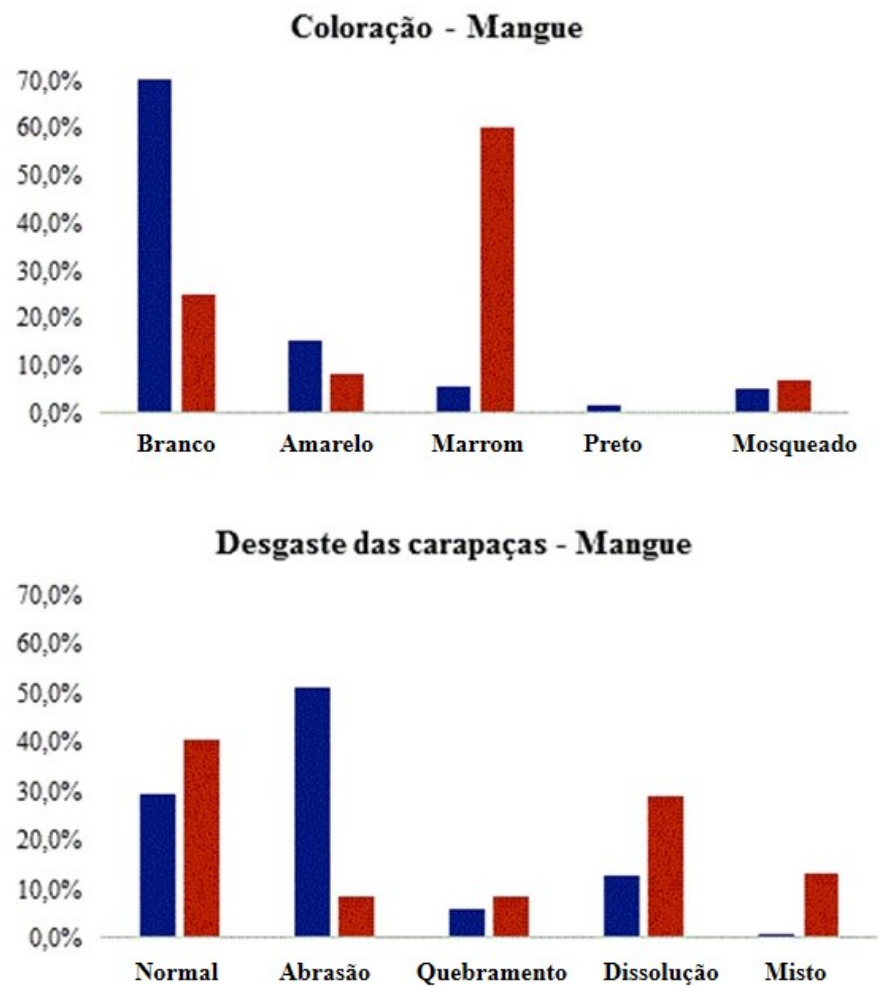

\section{Legenda: \\ - Periodo Chuvoso \\ = Periodo Seco}

Percentuais dos tipos de coloração e desgaste das espécies de foraminíferos na Zona de Manguezal do rio Jequitinhonha, referentes às campanhas de nov/2011 e abr/2012

O resultado da análise de Correlação Linear de Pearson para o período chuvoso (nov/2011), mostrou uma associação positiva entre os foraminíferos mortos com silte e argila devido à sua deposição preferencial em condições de baixa energia hidrodinâmica, enquanto que a relação negativa com $\mathrm{o} \mathrm{Eh}$, indica novos sedimentos sendo depositados sobre condições redutoras. Já a correlação negativa destes com areia fina, deve-se provavelmente, ao fato do manguezal ser um ambiente protegido contra ondas e correntes, sendo inundando com água salobra, o que consequentemente torna os níveis de salinidade mais baixos, fazendo com que a ocorra um aumento das testas de foraminíferos mortos (Martins et al., 2011). A correlação negativa dos foraminíferos mortos com o $\mathrm{pH}$, deve-se ao fato de áreas mais protegidas e menos hidrodinâmica como os manguezais, contribuírem para a redução dos valores de $\mathrm{pH}$, tornando-os mais ácidos e influenciando no aumento de testas de foraminíferos mortos, visto que processos de dissolução de testas calcárias ocorrem em ambientes com $\mathrm{pH}$ a partir de 6,8 (Martins et al, 2015).

A correlação positiva entre foraminíferos vivos, salinidade e temperatura, deve-se possivelmente, ao fato das associações de foraminíferos vivos serem constituídas por espécies eurialinas e euritérmicas, devido a sua tolerância as variações de salinidade e temperatura (Murray, 2001).

Houve uma associação positiva entre Nitrogênio total e metais pesados em ambas campanhas amostrais, a qual justifica-se pelo fato do aumento das concentrações de metais pesados estarem diretamente relacionados a origem antrópica, uma vez inserido no ambiente os metais interagem por processos de adsorção criadas por condições de nãoequilíbrio (Loureiro et al., 2012), o que é corroborado através das elevadas concentrações de Nitrogênio Total, oriundas de efluentes urbanos e industriais da região de estudo. 


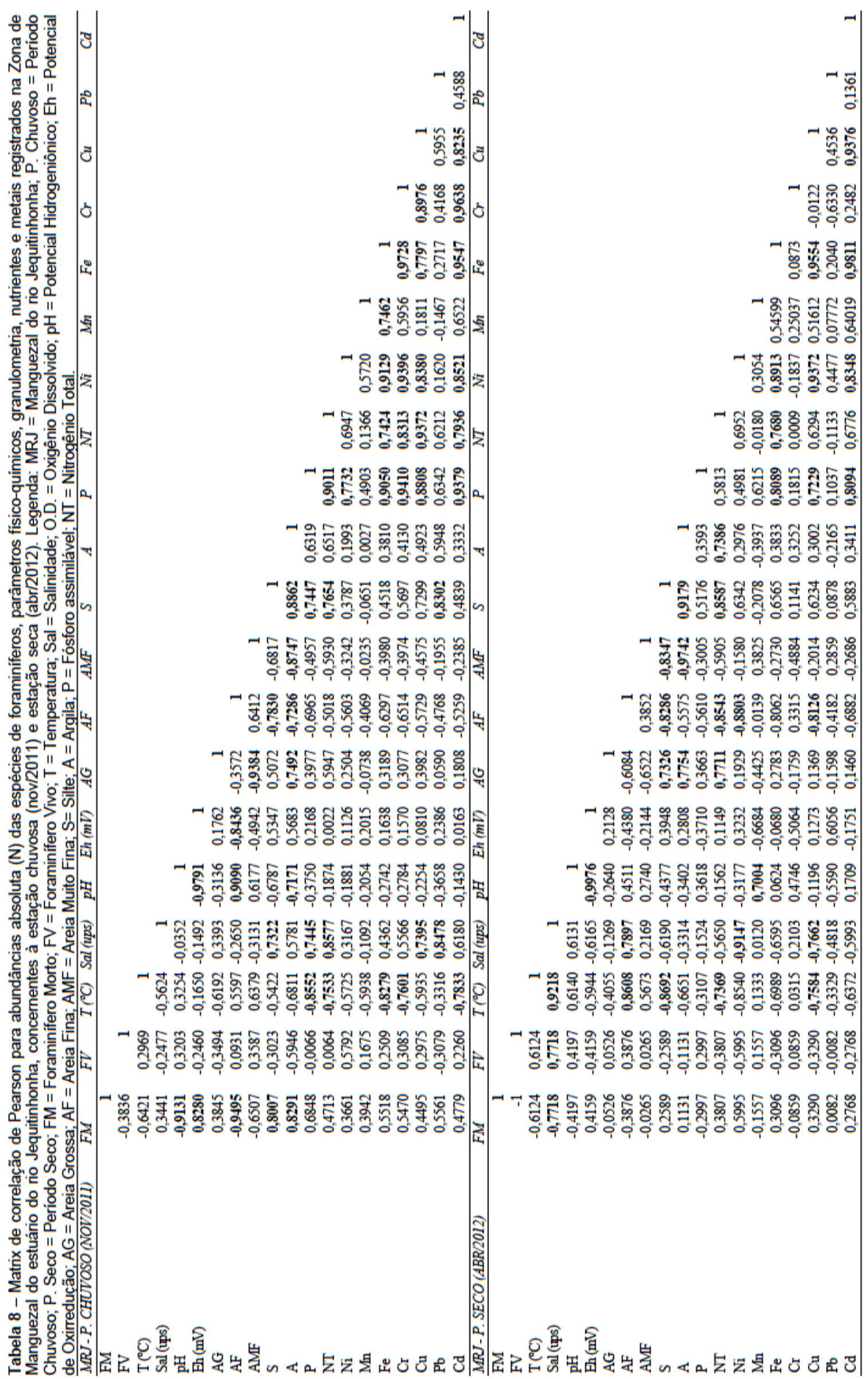




\section{CONCLUSÕES}

O canal do rio Jequitinhonha é constituído por águas doces em todos os 10 pontos, tanto no período chuvoso (nov/2011) quanto no período seco (abr/2012), com exceção apenas para o ponto 2 da estação seca que apresentou água salobra e levemente oxigenada.

Os baixos valores de salinidade encontrados no rio Jequitinhonha, deve-se a predominância de água fluvial em relação as marés, o que configura o Jequitinhonha como um Delta. Assim, o Jequitinhonha é um ambiente fluviodeltáico, apresentando grande descarga de água doce e deposição de sedimentos finos, siltosos e argilosos na bacia costeira.

A condição de delta para o rio Jequitinhonha foi corroborada através da granulometria, visto que para o canal houve predomínio da fração areia fina, enquanto que para o manguezal a predominância foi para as frações areia muito fina e silte, confirmando a expectativa de uma condição de menor energia hidrodinâmica para o rio.

Durante o período chuvoso (nov/2011) o sedimento é ligeiramente ácido a neutro e marcantemente redutor. Além disso, as concentrações de fósforo assimilável, níquel, ferro e cromo no canal, provavelmente originem-se da drenagem de áreas agrícolas à montante. Já no período seco (abr/2012), evidenciou concentrações de nitrogênio total, possivelmente devido aos efluentes urbanos e industriais que, assim como as concentrações de cádmio, ficam mais concentrados na estação seca.

No canal do rio Jequitinhonha, no período chuvoso (nov/2011), foram obtidos 281 indivíduos, destacando-se as espécies Trochammina inflata (37,0\%), Haplophragmoides wilberti (22,8\%) $e$ Ammonia beccarii $(18,5 \%)$ como as espécies principais. Já a espécie $A$. beccarii é a mais tolerante às grandes mudanças na temperatura e salinidade e também apresentam preferência por sedimentação fina com aporte de nutrientes. A maioria das testas exibiu coloração branca ou incolor $63,70 \%$ ou amarela 25,62\%. Quanto ao desgaste, $44,48 \%$ das testas estavam normais, mas $29,89 \%$ apresentaram sinais de abrasão.

No período chuvoso (nov/2011), a distribuição dos indivíduos vivos foi positivamente correlacionada à fração argila, indicando que a sedimentação fina possui maior conteúdo orgânico, evidenciando uma associação direta entre a textura do sedimento e os foraminíferos bentônicos. Já as testas dos indivíduos mortos apresentam correlação negativa com o Eh, visto que, todos os pontos, com exceção do ponto 10 , apresentaram valores negativos para o parâmetro $\mathrm{Eh}$, o geralmente é um indicativo de ambientes com sinais de hipóxia.

No período seco (abr/2012), a não ocorrência de foraminíferos se deve aos baixos valores de salinidade, o que impossibilitou a sobrevivência até mesmo das espécies mais resistentes. Apesar disso não houve dominância de espécies, embora os valores de riqueza e diversidade tenham sido baixos em relação a outros estuários.

O predomínio de testas brancas é indicativo de uma taxa de deposição muito rápida, com muito material novo sendo adicionado ao sedimento, principalmente durante a estação seca (abr/2012), o que é corroborado pelo domínio de testas normais.

Para a zona de manguezal do rio Jequitinhonha o aumento dos valores de salinidade e temperatura, durante a estação seca (abr/2012), podem estar relacionados à redução do volume de água. Apresenta uma sedimentação ligeiramente ácido a neutro e predominantemente oxidante.

As concentrações de fósforo assimilável e nitrogênio foram oriundas das águas marinhas que tendem a diluir suas concentrações na foz, tornando-se mais intensa no período chuvoso (nov/2011). Já os teores de cádmio, cromo, chumbo, ferro e zinco devem ser resultantes de fontes antrópicas, como os efluentes domésticos e drenagens agrícolas em atividades de carcinicultura, enquanto que o níquel é provavelmente resultante das atividades de mineração e descartes industriais na região.

$\mathrm{Na}$ zona de manguezal foram obtidos 116 indivíduos, sendo que não foram encontrados testas no ponto 6 e apesar das elevadas concentrações de metais traços, não houve registro de testas anômalas em nenhum dos pontos. Nessa amostragem, foram identificadas 10 espécies, destacando-se Haplophragmoides wilberti (37,1\%), Ammonia beccarii (32,8\%), Quinqueloculina fusca $(12,1 \%)$ e Q. venusta $(5,2 \%)$. A ocorrência de tais espécies deve-se ao fato destas serem mais tolerantes às grandes mudanças de salinidade e temperatura. Além disso, as espécies $H$. wilberti e $A$. beccarii são as mais tolerantes à contaminação por metais traços. Durante a estação seca (abr/2012), 
foram obtidos 143 foraminíferos, sem o registro de testas anômalas, identificadas 10 espécies, com predomínio de $H$. wilberti $(55,9 \%)$, Trochammina inflata $(19,6 \%)$ e $Q$. fusca $(7,0 \%)$. O aumento do número de testas, deve-se ao aumento significativa da salinidade, durante a estação seca (abr/2012).

$\mathrm{Na}$ estação chuvosa (nov/2011), a maioria das testas exibiu coloração branca ou incolor $72,27 \%$ e no período seco (abr/2012), a predominância foi de testas de coloração marrom 60,00\%. Quanto ao desgaste, o percentual daquelas abrasadas foi de 51,26\%, enquanto que as testas normais compunham um conjunto de $40,60 \%$.

\section{AGRADECIMENTOS}

Os autores agradecem a Coordenação de Aperfeiçoamento de Pessoal de Nível Superior (CAPES) pela concessão da bolsa do mestrado, Á Queiroz Galvão Exploração e Produção, pelo financiamento através do Projeto "Diagnóstico Geoambiental de Zonas de Manguezal e Desenvolvimento de Processos Tecnológicos Aplicáveis a Remediação dessas

\section{REFERÊNCIAS}

Azevedo, J. S.; Braga, E. S. 2011. Caracterização hidroquímica para qualificação ambiental dos estuários de Santos - São Vicente e Cananéia. Arquivos de Ciências do Mar, Fortaleza, 44(2):52-61.

Azevedo, J.S.; Braga, E.S.; Favaro, D.T.; Perretti, A.R.; Rezende, C.E.; Souza, C.M.M. 2011. Total mercury in sediments and in Brazilian Ariidae catfish from two estuaries under different anthropogenic influence. Marine Pollution Bulletin, 62(12): 2724-2731.

Ab'Saber, A. N.; Tundisi, J.G.; Forneris, L.; Marino, M.C.; Rocha, O.; Tundisi, T.; Schaeffer-Novelli, Y.; Vouno, Y.S.; Watanabe, S., 1997. Glossário de ecologia. 2a Ed. São Paulo, Aciesp, 352 p. (Publ. 103).

BRASIL. Ministério do Meio Ambiente. Conselho Nacional de Meio Ambiente, CONAMA. Resolução CONAMA no 454, 01 nov. 2012. Disponível em:

$<$ http://www.mma.gov.br/port/conama/legiabre.cfm ?codlegi=693>. Acesso em 13 mar. 2014.

BRASIL. Ministério do Meio Ambiente. Conselho Nacional de Meio Ambiente, CONAMA. Resolução CONAMA no 357, 17 mar. 2005. Disponível em:

$<$ http://www.mma.gov.br/port/conama/legiabre. cfm?codlegi=459>. Acesso em: 13 mar. 2014.
Assim, o domínio de testas brancas resulta da adição rápida de testas novas ao sedimento. Entretanto, houve também um alto percentual de testas abrasadas, as quais indicam condições de alta energia. Considerando-se que a maioria dos espécimes abrasados era da espécie $A$. beccarii e que esta também vive no canal estuarino do rio Jequitinhonha, é possível que parte das testas tenha sido transportada para dentro do manguezal.

No período seco (abr/2012), houve predomínio de testas marrons, sugerindo uma lenta taxa de sedimentação, causada por um intenso, porém não rápido, trabalho de erosão ou de bioturbadores, o que é confirmado pelo predomínio de testas normais.

Zonas: Subsídios a um Programa de Prevenção de Impactos em Áreas com Potencial para Atividades Petrolíferas na Região Litoral Sul do Estado da Bahia (PETROTECMANGUEBASUL)" e a Pós-graduação em Geoquímica, Petróleo e Meio Ambiente (POSPETROUFBA), pela oportunidade de realização deste trabalho.

Bouillon, A.V.; Borges, E.; Catañeda-Moya, K.; Diele, T.; Dittmar, N.C.; Duke, E.; Kristensen, S.Y.; Lee, C.; Marchand, J.J.; Middelburg, V.H.; Rivera-Monroy, T.J.; Smith, R.R.T. 2008. Mangrove production and carbon sinks: a version of global budget estimate Global Biogeochem. Global Biogeochemical Cycles, 22(2):1-12.

Berrêdo, J.F.; Costa, M.L.; Progene, M.P.S. 2008. Efeitos das variações sazonais do clima tropical úmido sobre as águas e sedimentos de manguezais do estuário do rio Marapanim, costa nordeste do Estado do Pará. Revista Acta Amazonica, 38(3):473-482.

Bastos, R.B. 2002. Variação espaço-temporal da biomassa fitoplanctônica relacionada com parâmetros abióticos no estuário do rio Una (Pernambuco, Brasil). Monografia (Graduação em Biologia) - Centro de Ciências Biológicas, Universidade Federal de Pernambuco, Recife, $56 \mathrm{p}$.

Celino, J.J.; Escobar, N.F.C.; Hadlich, G.M.; Nascimento, R.A.; Queiroz, A.F.S. Geoquímica da água superficial nos baixos cursos dos rios Una, Pardo e Jequitinhonha, Sul da Bahia. In: Celino, J.J.; Hadlich, G.M.; Queiroz, A.F.S.; Oliveira, O.M.C. (Orgs.). 2014. Avaliação de ambientes costeiros da região sul da Bahia: geoquímica, petróleo e sociedade. Salvador: EDUFBA, p.63-76. 
Cosentino, D.; Bertini, A.; Cipollari, P.; Florindo, F.; Gliozzi, E.; Grossi, F.; Lo Mastro, S.; Sprovieri, M. 2012. Orbitally forced paleoenvironmental and paleoclimate changes in the late post evaporitic Messinian of the central Mediterranean Basin. The Geological Society of America Bulletin, 124(3-4):499-516.

Cruz, F.C. Elementos traço em substrato de manguezais dos municípios de Una, Canavieiras e Belmonte, Bahia. 2012. Dissertação (Mestrado em Geoquímica) - Instituto de Geociências, Universidade Federal da Bahia, Salvador, $110 \mathrm{p}$.

Carvalho, P.V.; Santos, P.J.; Botter-Carvalho, M.L. 2010. Assessing the severity of disturbance for intertidal and subtidal macro benthos: the phylum-level meta-analysis approach in tropical estuarine sites of northeastern Brazil. Marine Pollution Bulletin, 60(6): 873-87.

Clarke, K.R.; Warwick, R.M. 2001. Change in marine communities: an Approach to Statistical Analysis and Interpretation. 2nd ed. [s.1.]: Plymouth Marine Laboratory, $172 \mathrm{p}$.

Donnici, S.; Serandrei-Barbero, R.; Bonardi, M.; Sperle, M. 2012. Benthic foraminifera as proxies of pollution: The case of Guanabara Bay (Brazil). Marine Pollution Bulletin, 64(10): 2015-2028.

Dajoz, R. 1983. Ecologia geral. 2.ed. Petrópolis: Vozes, $472 \mathrm{p}$.

Escobar, N.F.C.; Celino, J.J.; Nascimento, R.A. 2014. Metais na água superficial, material particulado em suspensão e no sedimento de fundo nos baixos cursos dos rios Una, Pardo e Jequitinhonha. In: CELINO, J.J.; HADLICH, G.M.; QUEIROZ, A.F.S.; OLIVEIRA, O.M.C. (Orgs.). Avaliação de ambientes costeiros da região sul da Bahia: geoquímica, petróleo e sociedade. Salvador: EDUFBA, 77-98 p.

Escobar, N.F.C. 2013. Geoquímica da água superficial e do sedimento de fundo nos baixos cursos dos rios Una, Pardo e Jequitinhonha, Sul da Bahia, Brasil. Dissertação (Mestrado em Geoquímica) - Instituto de Geociências, Universidade Federal da Bahia, Salvador, 107 p.

Gómes, E.; Bernal, G. 2013. Influence of the environmental characteristics of mangrove forests on recent benthic foraminifera in the Gulf of Urabá, Colombian Caribbean. Ciências Marinas, 39(1):69-82.

Gomes, R.C.T. 2010. Caracterização da fauna de foraminíferos da zona euhalina do estuário do rio Jacuípe - Camaçari-Ba. 2010. Tese (Doutorado em Geologia) - Instituto de Geociências, Universidade Federal da Bahia, Salvador, $100 \mathrm{p}$.

Jesus, B.S. 2015. Caracterização da geoquímica e comunidade cladocera dos estuários do rio Una, Una e rio Jequitinhonha, Belmonte, Bahia, Brasil. Dissertação (Mestrado em Geoquímica) Instituto de Geociências, Universidade Federal da Bahia, Salvador, 113 p.

Laut, L.L.M.; Cabral, I.A.; Rodrigues, M.A.C.; Silva, F.S.; Martins, M.V.A.; Boski, T.; Gomes,
A.I.; Dias, J.M.A.; Fontana, L.F.; Laut, V.M.; Mendonça-Filho, J.G. 2014. Compartimentos Ambientais do Estuário do Rio Arade, Sul de Portugal, com Base na Distribuição e Ecologia de Foraminíferos. Anuário do Instituto de Geociências - UFRJ, 37(2):60-74.

Loureiro, D.; Fernandez, M.; Herms, F.; Araújo, C.; Lacerda, L.D De. 2012. Distribuição dos metais pesados em sedimentos da lagoa Rodrigo de Freitas. Revista Oecologia Australis, 16(3):353364.

Lemos Júnior, I.C. 2011. Distribuição e aspectos tafonômicos de foraminíferos recentes na Plataforma Continental de Sergipe, Brasil. Dissertação (Mestrado em Geologia) - Instituto de Geociências, Universidade Federal da Bahia, Salvador, 73p.

Lamparelli, C.C. 2007. Commissioning and monitoring challenges regarding ocean outfalls: São Paulo State experience. In: Lamparelli, C.C.; Ortiz, J.P. (Eds.). Submarine outfalls: design, compliance and environmental monitoring. São Paulo: Secretaria do Meio ambiente, 11-23 p.

Martins, M.V.A.; Laut, L.L.M.; Silva, F.S.; Miranda, P.; Medonça-Filho, J.G.; FernándezFernández, S.; Sousa, S.S.; Rodrigues, M.A.C.; Rodrigues, A.R.; Yamashita, C.; Faria, E.O.; Oliveira, R.R.; Nagai, R.H. 2015. Associações de Foraminíferos em Resposta a Variações Ambientais da Laguna de Aveiro - Portugal, 38(2):56-69.

Martins, R.V.; Filho, P.F.J.; Eschrique, S.A.; Lacerda, L.D. 2011. Anthropogenic sources and distribution of phosphorus in sediments from the Jaguaribe River estuary, NE, Brazil. Brazilian Journal of Biology, 71(3):673-678.

Machado, A.J.; Araújo, H.A.B. 2011. Composição da Microfauna de Foraminíferos da Área recifal de Abrolhos, Bahia. Revista Gravel, 09(1):1124.

Martins, M.V.A.; Da Silva, E.F.; Sequeira, C.; Rocha, F.; Duarte, A.C. 2010. Evaluation of the ecological effects of heavy metals on the assemblages of benthic foraminifera of the canals of Aveiro (Portugal). Estuarine, Coastal and Shelf Science (Print), 87(2):293-304.

Murray, J.W. 2001. The niche of benthic foraminifera, critical thresholds and proxies. Marine Micropaleontology, 41(1-2):1-7.

Murray, J.W. 2006. Ecology and applications of benthic foraminifera. England: Cambridge University Press, 426 p.

Paula Filho, P.F.J.; DE MOURA, M.C.S.; MARINS, R.V. 2012. Phosphorus Geochemical Fractioning in Water and Sediment from Corrente River, Catchment, Parnaíba/PI. Revista Virtual de Química, 4(6):623-640.

Queiroz, A.F.S.; Oliveira, O.M.C. 2013. Diagnóstico geoambiental de zonas de manguezal e desenvolvimento de processos tecnológicos aplicáveis a remediação dessas zonas: subsídios a um programa de prevenção 
de impactos em áreas com potencial para atividades petrolíferas na região litoral sul do Estado da Bahia (PETROTECMANGUEBASUL). Salvador. Editora UFBA, 148p. 1 mapa, colorido. Escala 1:50.000.

Rodrigues, A.R.; Eichler, P.P.B.; Eichler, B.B. 2003. Utilização de foraminíferos no monitoramento do canal de Bertioga (SP, Brasil). Atlântica, Rio Grande, 25(1):35-51.

Saraswat, R.; Kouthanker, M.; Kurtarkar, S.R.; Nigam, R.; Naqvi, S.W.A.; Linshy, V.N. 2015. Effect of salinity in duced $\mathrm{pH} /$ alkalinity changes on benthic foraminifera: A laboratory culture experiment. Estuarine, Coastal and Shelf Science, 153(5):96-107.

SILVA, O.R. E GOMES, M.B.M. 2012. Impactos das atividades portuárias no sistema estuarino de Santos. Revista Metropolitana de Sustentabilidade. 2(2):64-81.

Semensatto-Jr., D.L.; Funo, R.H.F.; Dias-Brito, D.; Coelho-Jr., C. 2009. Foraminiferal ecological zonation along a Brazilian mangrove transect: Diversity, morphotypes and the influence of subaerial exposure time. Revue de Micropaléontologie. 52:67-74.
Sutherland, T.F.; Levings, C.D.; Petersen, S.A.; Piercey, B. 2007. The use of meiofauna as an indicator of benthic organic enrichment associated with salmonid aquaculture. Marine Pollution Bulletin. 54:1249-1261.

Teodoro, A.C.; Duleba, W.; Gubitoso, S.; Prada, S.M.; Lamparelli, C.C.; Bevilacqua, J.E. 2010. Analysis of foraminifera assemblages and sediment geochemical properties to characterise the environment near Araçá and Saco da Capela domestic sewage submarine outfalls of São Sebastião Channel, São Paulo State, Brazil. Marine Pollution Bulletin, 60:536-553.

Teodoro, A.C.; Duleba, W.; Lamparelli, C.C. 2009. Associações de foraminíferos e composição textural da região próxima ao emissário submarino de esgotos domésticos de Cigarras, Canal de São Sebastião,SP, Brasil. Pesquisas em Geociências, 36(1):467-475.

Veiga, J.E. 2010. Indicadores de sustentabilidade. Estudos Avançados, 24(68):39-52.

Zourarah, B.; Maanam, M.; Robin, M. 2009. Sedimentary records of anthropogenic contribution to heavy metal content in Oum Er Bia estuary (Morocco). Environmental Chemistry $\quad$ Letters, 